\title{
Comments on nutritional recommendations for CoVID-19 quarantine
}

\author{
Iván Herrera-Peco $\mathbb{1}^{1,2} \cdot$ Beatriz Jiménez-Gómez ${ }^{1}$ Juan José Peña-Deudero ${ }^{3}$ Elvira Benítez De Gracia ${ }^{3}$
}

Received: 7 December 2020 / Revised: 22 December 2020 / Accepted: 7 January 2021 / Published online: 19 March 2021

(c) The Author(s), under exclusive licence to Springer Nature Limited 2021

\section{To the Editor:}

We have read with interest the manuscript of Muscogiuri et al. entitled "Nutritional recommendations for CoVID-19 quarantine" [1]. The authors concluded that keeping foods sources of immuno-supportive nutrients, planning times to eat and meals, but having in mind positive attitudes could be helpful to avoid the negative health effects of quarantine. After a detailed review, we would like to highlight the attention to the part of the literature review performed in this review, which we believe does not do justice to the considerable effort made by the author and that could generate uncertainty on conclusions exposed by Muscogiuri et al.

Muscogiuri et al.'s manuscript include the Chandra's study [2] to support that anti-oxidants increase the T cells, interleukine-2 production, potential natural killer cell activity and increased response to influenza virus vaccine compared with placebo [1]. It is necessary to indicate that Chandra's study is a part of one of the major scientist fraud detected to date in Canadian institutions, being retracted from Lancet journal in 2016 [3] due to the following reason: (1) exists concerns about the authorship, (2) exists evidence of ethical violations by authors, (3) unreliable data and (4) results are unreliable, among others.

We conclude that the exclusion of Chandra's study does not probably affect the overall conclusions of Muscogiuri et al.'s study, but it affects directly to the particular conclusion exposed by Muscogiuri et al because Chandra's study failing to provide valid scientific evidence. Our intention is only to emphasize the importance of an accurate review of the literature and especially to bring to the attention of researchers about the use of retracted literature by scientific misconduct is a real danger that affects the safest way to improve decision-making in clinical practice $[4,5]$.

A good and accurate literature review is a key element of research studies and always needs to be based on high quality original studies and logically never retracted, this is why is necessary the implementation of tools that helps to researchers in their literature review to detect retracted articles. The issue raised here has been identified through the use of SCRUTATIOm [6], a fast, reproducible and systematic method for detecting retracted literature included in research studies [7].

Author contributions BJG, JJPD, EBDG, and IHP have participated in conceptualization, elaboration, and drafting of the manuscript.

\section{Compliance with ethical standards}

Conflict of interest The authors declare no competing interests.

Publisher's note Springer Nature remains neutral with regard to jurisdictional claims in published maps and institutional affiliations.

\section{References}

1. Muscogiuri G, Barrea L, Savastano S, Colao A. Nutritional recommendations for CoVID-19 quarantine. Eur J Clin Nutr. 2020;74850:74851

2. Chandra RK. Effect of vitamin and trace-element supplementation on immune responses and infection in elderly subjects. Lancet. 1992;340:1124-7

3. No authors listed. Retraction- effect of vitamin and trace-elements supplementation on immune responses and infection in elderly subjects. Lancet. 2016;387:417. https://doi.org/10.1016/S01406736(16)00166-5

\footnotetext{
Iván Herrera-Peco

iherrpec@uax.es

1 Nursing Department, Faculty of Health Sciences, Alfonso X el Sabio University, Avda. Universidad 1, Villanueva de la Cañada, Madrid 28691, Spain
}

2 Foundation Alfonso X el Sabio University, Madrid 28691, Spain

3 Faculty of Health Sciences, Alfonso X el Sabio University, Madrid 28691, Spain 
4. Neale AV, Northrup J, Dailey R, Marks E, Abrams J. Correction and use of biomedical literature affected by scientific misconduct. Sci Eng Eth. 2007;13:5-24

5. Boisvert I, Clemesha J, Lundmark E, Crome E, Barr C, McMahon CM. Decision-making in audiology: balancing evidence-based practice and patient-centered care. Trends Hear. 2017;21:2331216517706397
6. Morán JM, Santillán-García A, Herrera-Peco I. SCRUTATIOm: how to detect retracted literature included in systematics reviews and meta-analysis using SCOPUS( $\odot$ y ZOTERO@. Gac Sanit. 2020; S0213-911130179

7. Sox HC, Rennie D. Research misconduct, retraction, and cleansing the medical literature: lessons from the Poehlman case. Ann Intern Med. 2006;144:609-613 